\title{
Effect of Dislocation Density in an Unrecrystallized Part of Austenite on Growth Rate of Recrystallizing Grain
}

\author{
Atsuhiko YOSHIE, Takashi FUJITA, ${ }^{1)}$ Masaaki FUJIOKA, ${ }^{1)}$ Kentaro OKAMOTO, ${ }^{2)}$ Hirofumi \\ MORIKAWA ${ }^{3)}$ and Hidesato MABUCHI ${ }^{1)}$ \\ Kimitsu R \& D Laboratory, Nippon Steel Corporation, Kimitsu, Kimitsu, Chiba-ken, 299-11 Japan. \\ 1) Steel Research Laboratories, Nippon Steel Corporation, Shintomi, Futtsu, Chiba-ken, 293 Japan. \\ 2) Nippon Steel Metal Products Co., Ginza, Chuo-ku, Tokyo, 104 Japan. $\quad 3)$ NS Techno-Research Co., Shintomi, Futtsu, \\ Chiba-ken, 293 Japan.
}

(Received on August 22, 1995; accepted in final form on November 29, 1995)

\begin{abstract}
The growth rate of recrystallizing austenite grains of Si-Mn steels and $\mathrm{Nb}$ added steels after hot deformation was investigated by measurement of the fraction of recrystallized austenite and recrystallized austenite grain size. The fraction of recrystallized austenite $\left(X_{c r}\right)$ at which the mechanism of recrystallization changed from nucleation and growth (NG) to site saturation (SS) was formulated as a function of $\mathrm{Nb}$ concentration and deformation conditions. According to the increase in deformation temperature and strain, $X_{\mathrm{cr}}$ increases while the increase in $\mathrm{Nb}$ in solution decreases $X_{\mathrm{cr}}$.

The growth rate of recrystallizing austenite was also formulated as a function of strain energy $\left(F_{v}\right)$ and $\mathrm{Nb}$ concentration. The growth rate decreases rapidly after deformation due to the decrease in $F_{\mathrm{v}}$. The growth rate also decreases $\mathrm{Nb}$ addition.
\end{abstract}

KEY WORDS: austenite; dislocation density; recovery; recrystallization; growth rate; grain size; $\mathrm{Nb}$; formulation; high strength steel; nucleation and growth; site saturation.

\section{Introduction}

In the hot rolling processes of steels, the phenomena such as work hardening, recovery and recrystallization of austenite $(\gamma)$ interact. Austenite transforms into a variety of microstructures after hot rolling and the transformation behavior depends largely on the microstructural state of $\gamma^{1,2)}$ Therefore, it is important to understand clearly the relationship between the rolling conditions and the microstructural changes taking place in $\gamma$. In the previous report, ${ }^{8,9}$ the present authors formulated the effects of $\mathrm{Nb}$ content and working conditions on work hardening and static recovery occuring in $\gamma$ which was hot worked in similar conditions to the plate rolling.

A number of reports are available on the recrystallization behavior of $\gamma$ following static recovery under hot rolling. ${ }^{3-7)}$ However, fundamental phenomena such as the transition from nucleation and growth (NG) to site saturation (SS) and the changes in nucleation rate $I$ and growth rate $G$ of recrystallized grains with progress of recrystallization are not well understood. Although the fraction of recrystallized $\gamma$ is known to be simply represented in an equation based on the Johnson-MehlAvrami equation, ${ }^{13,14)}$ it fails to include these phenomena and is limited in the range of application and calculation accuracy.

In the present report, the effects of $\mathrm{Nb}$ contents and deformation conditions on the fraction of recrystallized $\gamma$ associated with the transition from NG to SS will first be clarified. Then, formulation will be made for the growth rate of recrystallizing grains $G$ as a function of $\rho$ by calculating the changes in dislocation density due to hot deformation and subsequent static recovery based on the procedure reported in the previous paper. ${ }^{8,9)}$

\section{Steels Tested and Experimental Conditions}

Table 1 shows the chemical compositions of steels tested. The starting material with the base composition of $0.10 \% \mathrm{C}-1.35 \% \mathrm{Mn}$ (mass $\%$ ) was melted in a vacuum furnace, poured into three $100 \mathrm{~kg}$ ingots, among which two of the ingots had 0.01 and $0.03 \%$ of $\mathrm{Nb}$ added respectively. From the $100 \mathrm{~kg}$ ingots, square columns of $10 \mathrm{~mm}$ in thickness, $18 \mathrm{~mm}$ in width and $150 \mathrm{~mm}$ in length were machined for the quenching test after hot deformation and holding. In order to enhance the cooling rate in quenching, the hot deformed part of the specimens was thinned to a thickness of $5 \mathrm{~mm}$.

Table 1. Chemical compositions of steels tested. (mass\%)

\begin{tabular}{ccccccc} 
Steel & C & Si & Mn & Al & Nb & \multicolumn{1}{c}{ N } \\
\hline T0 & 0.10 & 0.20 & 1.37 & 0.027 & 0.0 & 0.0028 \\
T1 & 0.10 & 0.20 & 1.37 & 0.027 & 0.010 & 0.0028 \\
T3 & 0.10 & 0.20 & 1.37 & 0.027 & 0.030 & 0.0028 \\
\hline
\end{tabular}


The specimens were hot deformed under a predetermined condition in a hot deformation simulator of plain strain-compression type ${ }^{10)}$ and rapidly cooled by water spray after holding for a given time interval at the deformation temperature. The experiments were carried out by changing the reheating temperature (i.e. $\gamma$ grain size and amount of $\mathrm{Nb}$ in solution), deformation temperature, strain and holding time after deformation as shown in Fig. 1.

The specimens quenched after testing were cut into two pieces in the transverse direction. The section was prepared for optical microscopy by polishing and etching with picric acid for revealing the prior $\gamma$ grain boundaries. In addition, extraction replicas were prepared from the specimens quenched immediately after deformation for transmission electron microscopy. The observation of the extraction replicas revealed that both dynamic recrystallization of $\gamma$ and dynamic precipitation of $\mathrm{Nb}$ did not take place within the present experimental conditions.

By using the micrographs of continuous four fields with a magnification of 50 to 200 for the prior $\gamma$ grain structures, the fraction of recrystallized $\gamma$ and average $\gamma$ grain size were measured by the point counting method and the linear intercepting method respectively. The mean intercept length of grains was converted into the ASTM grain size. ${ }^{11)}$

\section{Experimental Results}

An example of recrystallization progress in the $\mathrm{Si}-\mathrm{Mn}$ steel reheated at $1200^{\circ} \mathrm{C}$ is shown in Fig. 2. The samples were deformed to a true strain of $\varepsilon=0.4$ and held at $900^{\circ} \mathrm{C}$ for various periods of time. Figure 2 shows some fine grains evolved along prior $\gamma$ grain boundaries, suggesting that recrystallization has started at $4 \mathrm{~s}$ after deformation. Recrystallization progressed with holding time and completed at about $1000 \mathrm{~s}$ after deformation. The average $\gamma$ grain size was $57 \mu \mathrm{m}$ after the completion of recrystallization.

Figure 3 shows the relationship between the holding time after deformation and the fraction of recrystallized $\gamma$. These data are the results of experiments carried out by changing the temperature of deformation and holding, $T, \varepsilon$, and $\mathrm{Nb}$ content. Recrystallization progressed more rapidly under the conditions of higher temperature of deformation and holding and also of higher deforma-

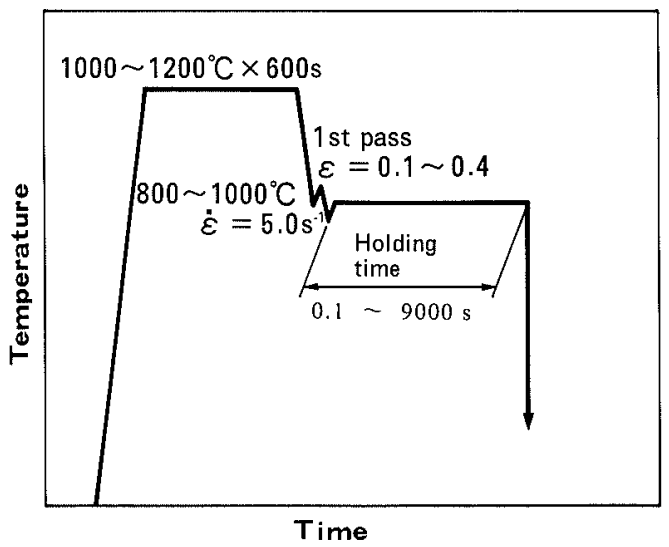

Fig. 1. Schematic illustration of experimental conditions.

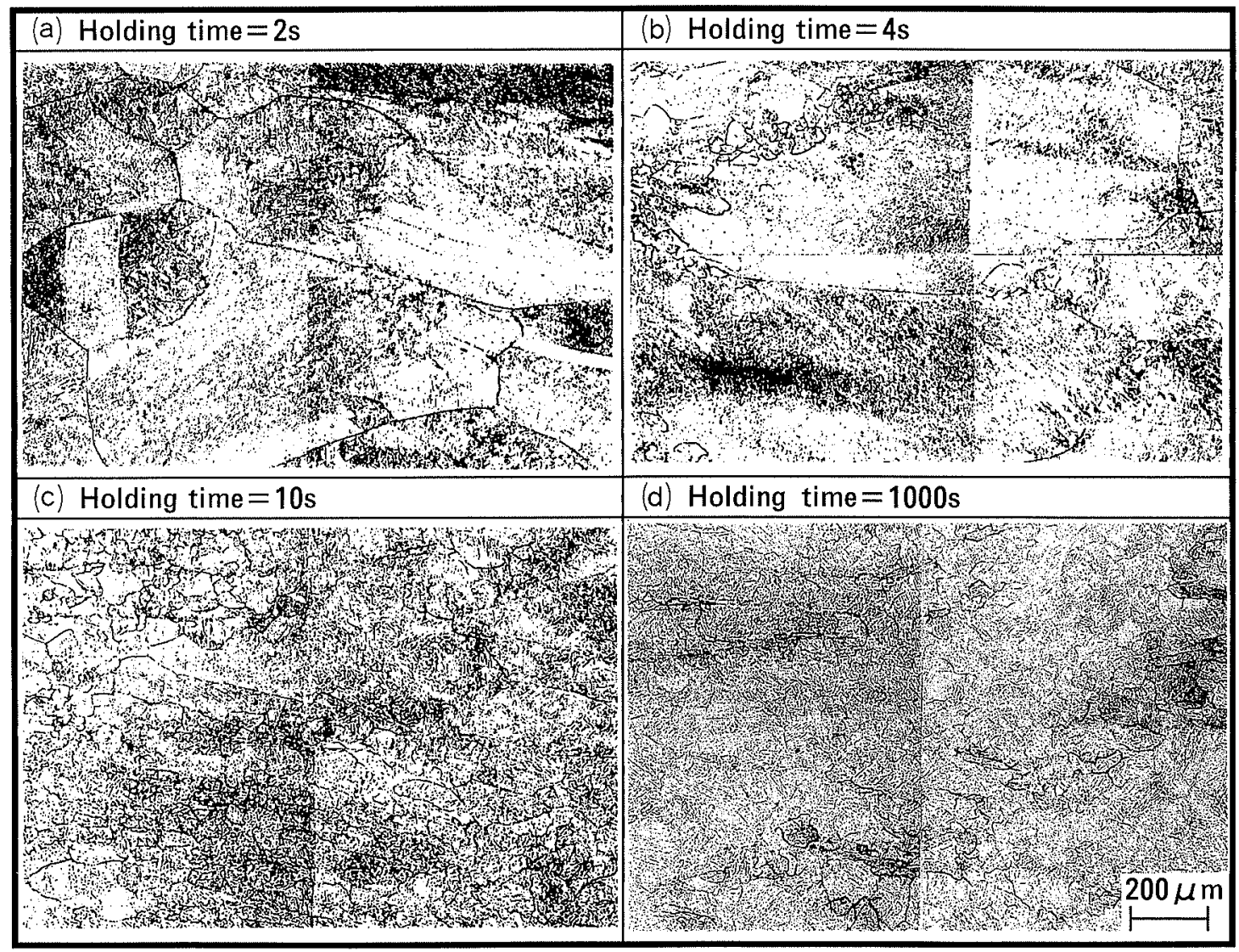

Fig. 2. Change in prior austenite structure during holding time $\left(0.01\right.$ mass $\% \mathrm{Nb}$, Reheating temp. $=1200^{\circ} \mathrm{C}$, Deformation temp. $=900^{\circ} \mathrm{C}, \varepsilon=0.4$ ). 


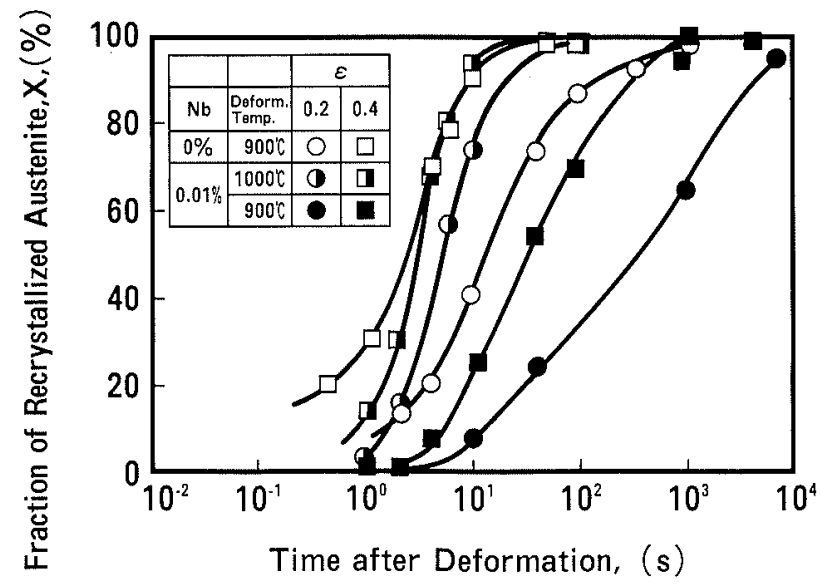

Fig. 3. Relation between holding time after deformation and fraction of recrystallized austenite (Reheating temp. $=$ $1200^{\circ} \mathrm{C}$ )

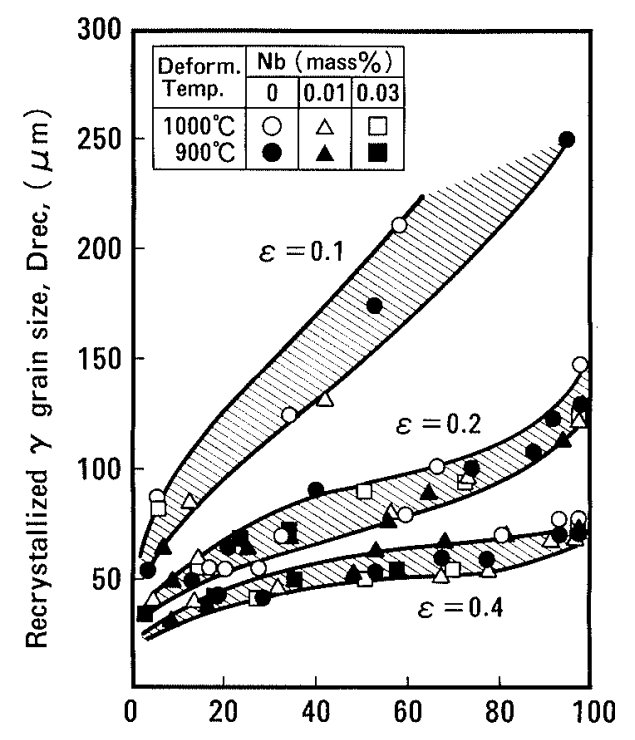

Fraction of recrystallized $\gamma, \mathrm{X},(\%)$

Fig. 4. Relation between fraction of recrystallized austenite and recrystallized austenite grain size (Reheating temp. $=1200^{\circ} \mathrm{C}$ ).

tion strain in $0.01 \% \mathrm{Nb}$ steel. For a given deformation condition, recrystallization is suppressed more in $0.01 \%$ $\mathrm{Nb}$ than in $\mathrm{Si}-\mathrm{Mn}$ steel. These results are similar to the previous report. ${ }^{12)}$

Since the time interval between passes in plate rolling is about $10 \mathrm{~s}$, the fraction of recrystallized $\gamma$ at the position of $10 \mathrm{~s}$ on the horizontal axis will give the information of recrystallized or unrecrystallized state between the passes in practical mills. When deformation is applied at $900^{\circ} \mathrm{C}$ to a strain of $\varepsilon=0.4$, the fraction of recrystallized $\gamma$ can be $95 \%$ in $\mathrm{Si}-\mathrm{Mn}$ steel and, on the other hand, $23 \%$ in $0.01 \% \mathrm{Nb}$. This suggests the effectiveness of microalloying of $\mathrm{Nb}$ for suppressing recrystallization.

Figure 4 shows the relationship between the fraction of recrystallized $\gamma$ and average $\gamma$ grain diameter $D_{\text {rec }}$ in the recrystallized regions. For every $\varepsilon, D_{\text {rec }}$ increases with increasing fraction recrystallized. $D_{\text {rec }}$ after completion of recrystallization can be determined mainly by the degree of $\varepsilon$, although it depends slightly on the de-

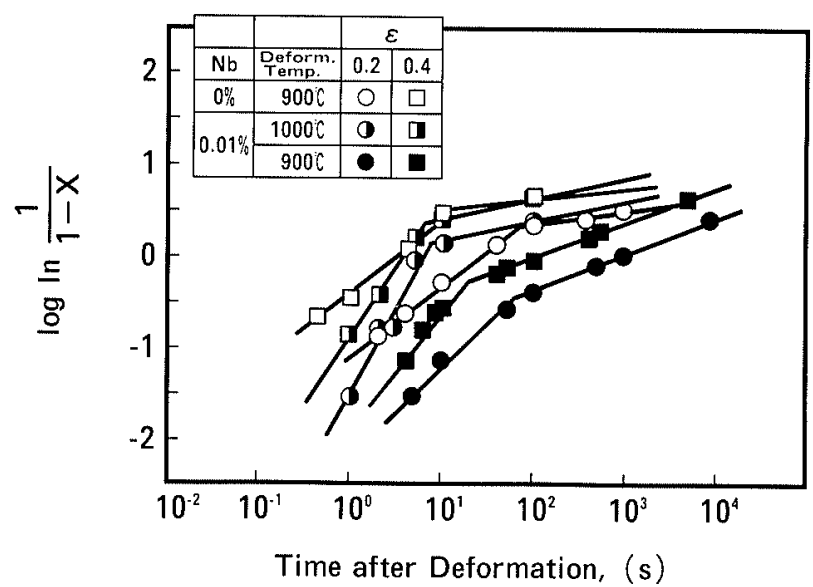

Fig. 5. Replot of relation between holding time after deformation and fraction of recrystallized austenite (Avrami plot, Reheating temp. $=1200^{\circ} \mathrm{C}$ ).

formation temperature and $\mathrm{Nb}$ content. As apparent in Fig. 3, the deformation temperature and $\mathrm{Nb}$ content influence the progress of recrystallization, but scarcely the diameter of recrystallized grains.

\section{Discussion}

\subsection{Recrystallization Mechanism}

The fraction of recrystallized $\gamma, X$, is expressed as Eq. (1) in the form of Johnson-Mehl-Avrami equation. ${ }^{13,14)}$ Making logarithmic transformation twice on Eq. (1) leads to Eq. (2), giving the Avrami plot of the inverse of $(1-X)$ vs. the logarithm of annealing time.

$$
\begin{array}{r}
X=1-\exp \left(-B t^{k}\right) \\
\log \{\ln [1 /(1-X)]\}=\log (B)+k \log (t)
\end{array}
$$

where $B$ and $k$ are constants, and $t$ is the annealing time after deformation.

The $X-t$ relations in Fig. 3 is replotted using Eq. (2) in Fig. 5. For all of the $\mathrm{Nb}$ contents and temperatures of deformation and holding, each plotted line has a deflection point with the different Avrami slope from 1-2 in the range of lower $X$ to 0.5 in that of higher $X$. By assuming a constant rate of nucleation and growth of recrystallizing grains, the equation derived by $\mathrm{Cahn}^{17)}$ for recrystallization rate of polycrystalline materials shows that the time index in the recrystallization process controlled by the NG mechanism is 4 regardless of the location of nucleation site such as grain boundaries, edges or corners. On the other hand, if recrystallization is controlled by the SS mechanism, the time index differs in accordance with the location of nucleation sites; 1 for grain boundaries, 2 for edges and 3 for corners of crystals. The time index becomes smaller for every nucleation site with the change in the mechanism from NG to SS. As the Avrami slope is time index of Eq. (1), the deflection in the plotted line can suggest the change in the recrystallization mechanism from NG to SS. However, the slopes shown in Fig. 5 is smaller than the values predicted by Cahn. As suggested by Vandermeer ${ }^{15}$ ) for $\mathrm{Al}$, this may be a result of decreases in $G$ and $I$ of recrystallizing grains due to recovery of unrecrystallized parts of $\gamma$. This point is disscussed later. 
In the next step, calculation was made for the number of grains $N_{\gamma}$, in a unit area $\left(1 \mathrm{~mm}^{2}\right)$. When the observed area is completely occupied with recrystallized grains, the number of grains per $1 \mathrm{~mm}^{2}$ is equal to $\left(D_{\mathrm{rec}} /\right.$ $1000)^{-2} .^{23)}$ At the fraction of recrystallized $X$, the area occupied by recrystallized grains is $X \mathrm{~mm}^{2}$ and $N_{y}$ is expressed by Eq. (3).

$$
N_{\gamma}=\left(1000 / D_{\text {rec }}\right)^{2} X
$$

The relationship between the fraction of recrystallized $\gamma, X$, and $N_{\gamma}$ under the same deformation conditions shown in Fig. 3 is illustrated in Fig. 6. The values of $N_{\gamma}$ are saturated at a certain point of $X$ and sometimes $N_{\gamma}$ decreases with increasing $X$ in the range of higher $X$. Since nucleation can be finished around the maximum $X, X_{\text {crn }}$, the recrystallization mechanism may change from NG to SS at around $X_{\text {crn }}$. Decrease in $N_{\gamma}$ in over $X_{\text {crn }}$ can be a result of coalescence of recrystallization grains. Since the decrement of $N_{\gamma}$ from the maximum is small

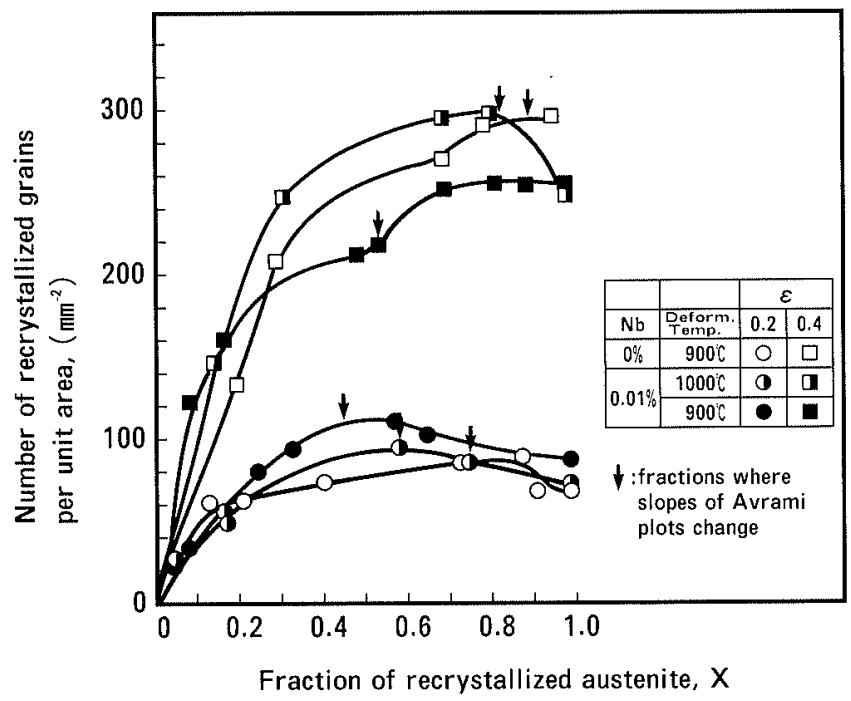

Fig. 6. Relation between fraction of recrystallized austenite and number of recrystallized grains per unit area (Reheating temp. $=1200^{\circ} \mathrm{C}$ ).

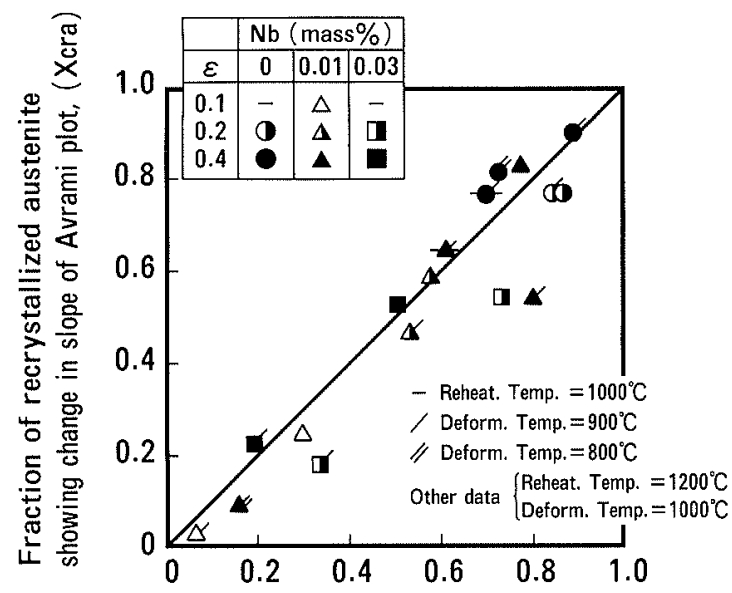

Fraction of recrystallized austenite showing maximum number of recrystallized grains, (Xcrn)

Fig. 7. Relation between fractions of recrystallized austenite showing maximum number of recrystallized grains $\left(X_{\mathrm{crn}}\right)$ and that showing change in slope of Avrami plot $\left(X_{\text {cra }}\right)$. enough to ignore in practical application, however, the effects of grain coalescence here are not taken into consideration.

Figure 7 compares the value of $X_{\text {cra }}$ defined at the point of deflection in Fig. 5 and the $X_{\text {crn }}$ indicated by the arrows in Fig. 6 . The close agreement between $X_{\text {cra }}$ and $X_{\text {crn }}$ suggests that both can represent the fractions of recrystallized $\gamma$ on change of the recrystallization mechanism from NG to SS. Since the $X_{\text {crn }}$ includes some errors due to the broad range of the maximum value, the values of $X_{\text {cra }}$ will be used as the fraction of recrystallized $\gamma$ corresponding to the change in recrystallization mechanism in the following analysis. The fact that the number of recrystallized grains saturate for $X \geqq X_{\text {cra }}$ was confirmed by the microstructural observation of specimens that were treated to vary the holding time under typical working conditions.

Basically, $X_{\text {cra }}$ follows Eq. (2) and $B$ in the equation is a function of $\gamma$ grain size before deformation $D_{\mathrm{l}}$, temperature of deformation and holding $T, \varepsilon$, and $\mathrm{Nb}$ content. Thus, the quantity of $X_{\text {cra }}$ was assumed to be expressed by Eq. (4) as a function of $D_{\mathrm{I}}, \varepsilon$, and content of added $\mathrm{Nb}\left(N b^{\mathrm{T}}\right)$ because recrystallization is controlled by a thermally activated process and the conventional simplified formula can give a good summary of the effects of $D_{1}$ and $\varepsilon$ in a form of exponential function. The constant for each factor was obtained with multiple regression analysis of all the data of $X_{\text {cra }}$. The result is shown in Eq. (4).

$$
X_{\text {cra }}=22.3 \varepsilon^{0.463} D_{\mathrm{I}}^{-0.0347} \exp \left(-32.6 N b^{\mathrm{T}}-3190 / T\right)
$$

where $D_{\mathrm{I}}$ is in the unit of $\mu \mathrm{m}, N b^{\mathrm{T}}$ in mass $\%$, and $T$ in $\mathrm{K}$.

This equation suggests that deformation to a higher strain enhances recrystallization by the NG mechanism to a higher fraction of recrystallization. This phenomenon is consistent with the observation results that the number of ferrite nuclei increase by applying the deformation of higher strains in the nonrecrystallization temperature region of austenite. ${ }^{16,24)}$ Equation (4) includes a small influence of $D_{1}$ and has a tendency of decrease in $X_{\text {cra }}$ with coarsening of initial grains. This

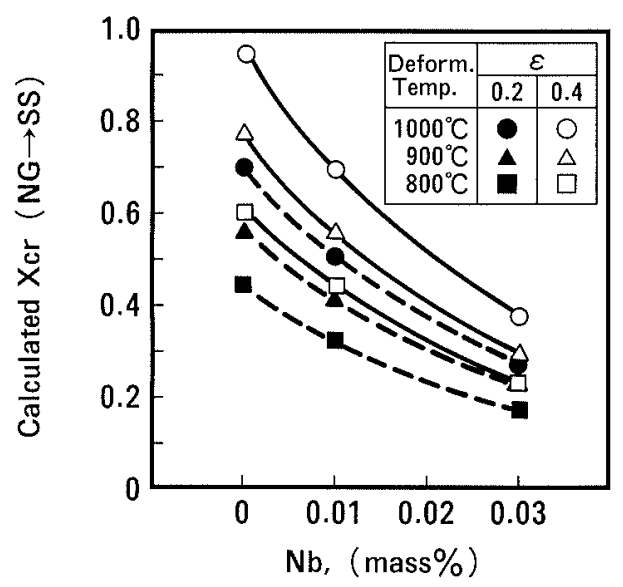

Fig. 8. Effects of $\mathrm{Nb}$ and deformation conditions on fraction of recrystallized austenite where mechanism of recrystallization changes from nucleation and growth to site-saturation, plot of Eq. (4). 
may be a result of the occupation of grain boundaries by recrystallized grains at the earlier stage because coarse grains have a smaller area of grain boundaries for a unit volume.

The relation between $N b^{\mathrm{T}}$ and $X_{\text {cra }}$ calculated from Eq. (4) is shown in Fig. 8. Transition from NG to SS occurs at a smaller fraction of recrystallized $\gamma$ for a higher $\mathrm{Nb}$ content in Fig. 8.

\subsection{Growth Rate of Recrystallizing Austenite Grain}

It is concluded from the previous discussions that recrystallization can proceed by the $\mathrm{NG}$ mechanism for $X \leqq X_{\text {cra }}$ and, on the other hand, by the SS mechanism for $X>X_{\text {cra }}$. Equation (5) holds for the progress of recrystallization by the SS mechanism in which recrystallized grains nucleate and grow from grain boundaries. $^{17)}$

$$
X=1-\exp \left(-2 S_{\gamma} G t\right)
$$

where $S_{\gamma}$ is the area of austenite grain boundaries per unit volume as expressed by Eq. (6) obtained from $D_{1}$ and $\varepsilon$ on the assumption that the grain shape is spheroidal. ${ }^{6)}$

$$
S_{\gamma}=\left(24 / \pi D_{1}\right)\left\{0.491 e^{\varepsilon}+0.155 e^{-\varepsilon}+0.143 e^{-3 \varepsilon}\right\}
$$

As a result of calculation of $G$ from Eq. (5) by using the $X-t$ relations for each $\mathrm{Nb}$ content and deformation condition, $G$ decreases monotonously with increasing $t$. This may be caused by decrease in the strain energy of unrecrystallized regions due to recovery. Equation (7) gives the growth rate as a function of lattice strain energy $F_{\mathrm{v}}$ in unrecrystallized regions based on the classical theory. ${ }^{18)}$

$$
G=\left(D_{\mathrm{GB}} / k T\right)\left(F_{\mathrm{v}} / N_{0} \lambda\right)
$$

where $D_{\mathrm{GB}}$ is the self diffusion constant at grain boundaries $\left(D_{\mathrm{GB}}=D_{\mathrm{GB} 0} \exp \left(-Q_{\mathrm{GB}} / R T\right)\right), k$ the Boltzmann's constant, $N_{0}$ the Avogadro's number, and $\lambda$ the thickness of grain boundaries. Further $F_{\mathrm{v}}$ is expressed by Eq. (9) in terms of the self energy of dislocation $\left(E_{\text {disl }}\right)$ per unit length ${ }^{19)}$ as given in Eq. (8). In the Eq. (8), $E_{\text {dis } 1}$ represents the value of an edge dislocation and the radius of dislocation core is taken as $1 / 4$ of Burgers' vector $b .^{20 \text { ) }}$

$$
E_{\mathrm{dis} 1}=\left[\mu b^{2} / 4 \pi(1-v)\right] \ln [(4 r / b)+1]
$$

where $\mu$ the shear modulus, $b$ the length of Burgers' vector $\left(2.6 \times 10^{-7} \mathrm{~mm}\right), v$ the Poisson's ratio $(0.333)$, and $r$ the average spacing of dislocations $\left(\rho_{\mathrm{r}}^{0.5} / 2\right.$ in the present study). The shear modulus is taken to be $8 \times 10^{4}$ $\mathrm{MPa}$ with reference to the data of austenitic stainless steel at room temperature and its temperature dependence is not taken into account in the present study.

$$
F_{\mathrm{v}}=E_{\mathrm{disl}} \rho_{\mathrm{r}}
$$

where $\rho_{\mathrm{r}}$ is the dislocation density in unrecrystallized regions of $\gamma$. The value of $\rho_{\mathrm{r}}$ was calculated with the functions of $\mathrm{Nb}$ content, deformation condition and holding time after deformation formulated in previous papers. ${ }^{89}$ ) As the observed flow stresses of the second pass in the double compression test in which the time interval between the first and the second passes changed from $0.1 \mathrm{~s}$ to $9000 \mathrm{~s}$ have been adopted in the formulation, ${ }^{9)}$ both $\rho_{\mathrm{r}}$ and $F_{\mathrm{v}}$ can be calculated properly since the start to the end of recrystallization process.

By selecting the data for $X \geqq X_{\text {cra }}$ in which recrystallization proceeds by the SS mechanism, the values of $F_{y}$ calculated with the above procedure were correlated with the values of $G$ calculated from Eq. (5) based on microstructural observation. An example at the reheating temperature of $1200^{\circ} \mathrm{C}$ and $\varepsilon=0.4$ is shown in Fig. 9 . Both are correlated in a linear relationship as predicted from Eq. (7) with a slope of about 1 . This means that $G$ decreases with progress of recovery (or decrease in dislocation density) taking place in unrecrystallized regions. It must be noted that this linear relationship is confirmed for the data observed in a later stage of recrystallization process. However, as the values of $F_{\mathrm{v}}$ in Fig. 9 change widely, this linear relationship may be kept in a range of larger $F_{\mathrm{v}}$. Figure 9 suggests that $G$ is strongly influenced by $\mathrm{Nb}$ content and temperature of deformation and holding as well as lattice strain energy $F_{\text {v. }}$.

Next, the formulation of $G$ was intended as a function of these influencing factors. By summarizing the constants in Eq. (7) as $A$ and applying the functional forms taking into account $\gamma$ grain diameter $D_{1}$ and $N b$ as used in the previous paper, ${ }^{8,9)} G$ is formulated as Eq. (10).

$$
G=A\left(F_{\mathrm{v}} / T\right) D_{1}^{\mathrm{B}} \exp \left(C \cdot N b^{\mathrm{sol}}+D \cdot N b^{\text {pre }}-E / T\right)
$$

where $A=D_{\mathrm{GBO}} / k N_{0} \lambda, N b^{\text {sol }}$ and $N b^{\text {pre }}$ are the amounts of solute $N b$ and precipitated $N b$ in mass \% respectively, $A, B, C, D$ and $E$ are constants. The amount of $N b^{\text {pre }}$ increases according to the time after deformation and $N b^{\text {pre }}$ is also affected by $T$ and $\varepsilon .^{12.25)}$ The $N b^{\text {pre }}$ used was calculated by using the Akamatsu's program ${ }^{21)}$ in which $N b^{\text {pre }}$ is formulated as a function of $T, \varepsilon$ and time after deformation. By using the calculated values of $F_{\mathrm{v}}$ as mentioned above and determining the values of $A$, $B, C, D$ and $E$ to minimize the difference of measured $G$ s and the values calculated from Eq. (10), the result

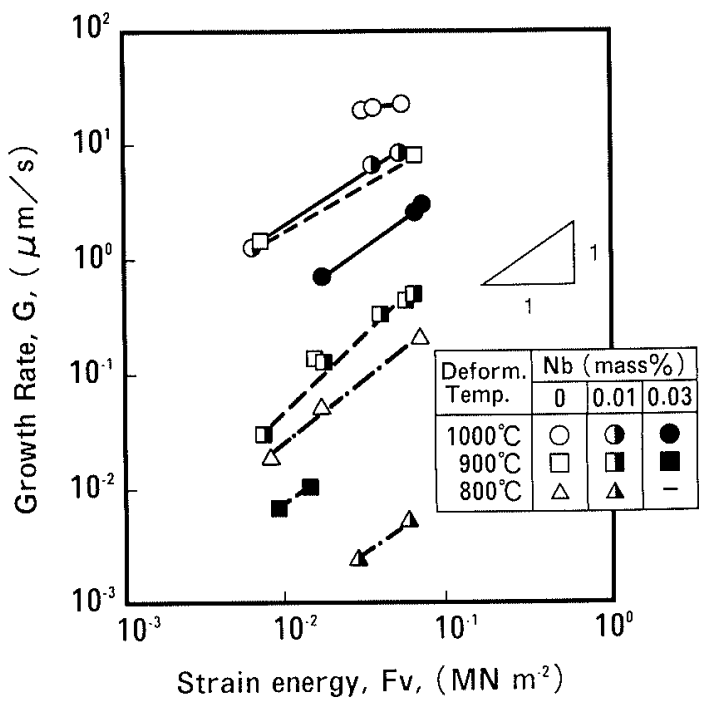

Fig. 9. Relation between estimated strain energy of the unrecrystallized part of deformed austenite and observed growth rate of recrystallizing grain (Reheating temp. $=1200^{\circ} \mathrm{C}, \varepsilon=0.4$ ) 


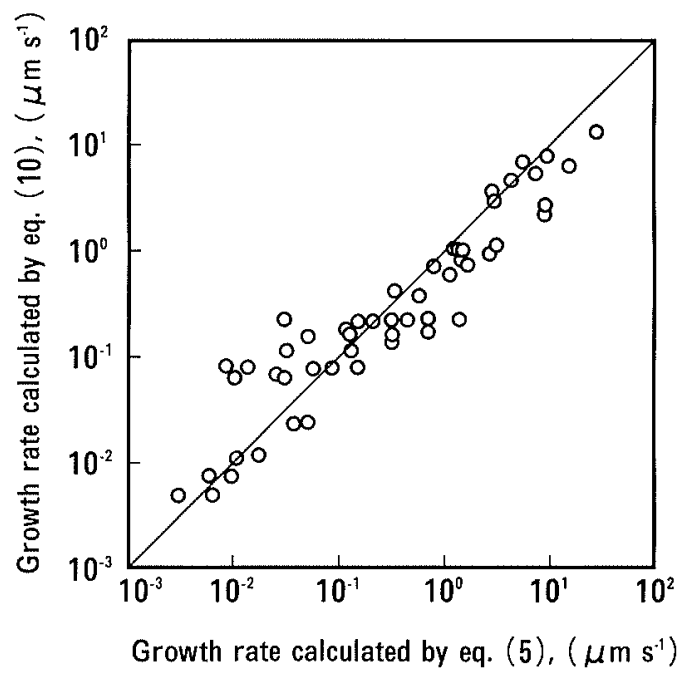

Fig. 10. Relation between growth rate of recrystallizing grain calculated by Eq. (5) and growth rate calculated by Eq. (10)

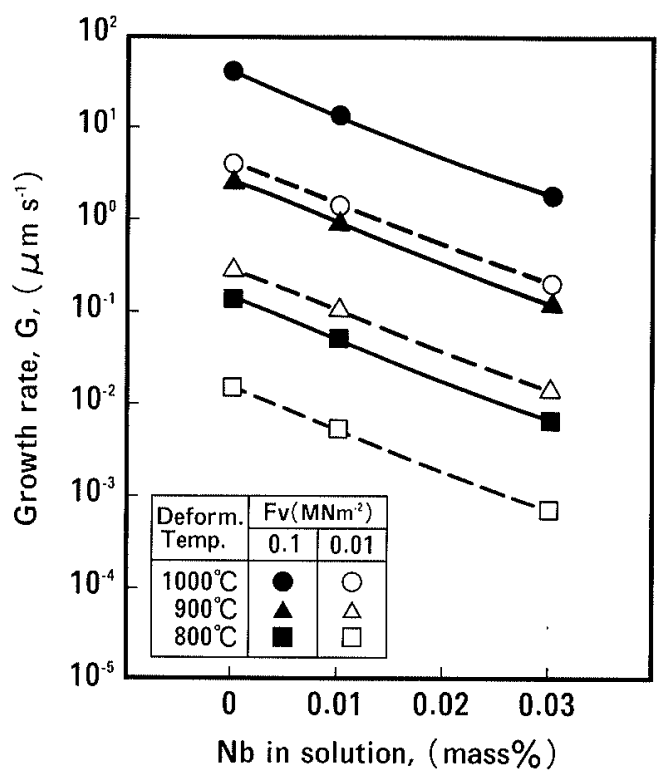

Fig. 11. Effects of $\mathrm{Nb}$ in solution and deformation conditions on calculated growth rate of recrystallizing grain (Reheating temp. $=1200^{\circ} \mathrm{C}$ ), plot of Eq. (10).

is that $A=7.46 \times 10^{16}\left(\mathrm{~m}^{3} \mathrm{kMN}^{-1} \mathrm{~s}^{-1}\right), B=-0.035$ $\left(\right.$ mass $\left.\%^{-1}\right), C=-108.0\left(\right.$ mass $\left.^{-1}{ }^{-1}\right), D=-142.0$ (mass $\%^{-1}$ ), and $E=41000.0(\mathrm{~K})$. The effect of $D_{\mathrm{I}}$ is very small. Moreover, $G$ is more strongly suppressed by precipitated $\mathrm{Nb}\left(\mathrm{Nb}^{\mathrm{pre}}\right)$ than solute $\mathrm{Nb}\left(\mathrm{Nb}^{\mathrm{sol}}\right)$.

Figure 10 compares the values of $G$ obtained by substituting the measured fraction of recrystallized $\gamma$ for $X$ in Eq. (5) with those calculated from Eq. (10). Both hold close agreement and the validity of Eq. (10) is confirmed. The effects of solute $\mathrm{Nb}$ content, temperature of deformation and holding and $F_{\mathrm{v}}$ on $G$ calculated by Eq. (10) are shown in Fig. 11. It is shown that $G$ decreases remarkably with increase in solute $\mathrm{Nb}$ content, lowering of deformation and holding temperature and decrease in $F_{\mathrm{v}}$.

\section{Conclusion}

The fraction of recrystallized $\gamma$ and recrystallized $\gamma$ grain size after hot deformation were examined in Si-Mn steel and $\mathrm{Nb}$ added steels. Based on the present work, the effect of recovery in unrecrystallized regions on the growth rate of recrystallizing $\gamma$ grains were analyzed. The results are summarized as follows.

(1) The recrystallization fraction $X_{\text {cra }}$, representing the change of the recrystallization mechanism from nucleation and growth (NG) to site saturation (SS), is formulated as a function of deformation conditions $(T, \varepsilon)$ and $\mathrm{Nb}$ contents. Deformation to high strains and holding at high temperatures retain nucleation up to higher fractions of recrystallization. A higher amount of solute $\mathrm{Nb}$ before deformation results in the transition of the recrystallization mechanism from NG to SS at lower fraction of recrystallization.

(2) The growth rate of recrystallizing $\gamma$ grain is formulated as a function of $\mathrm{Nb}$ content and lattice strain energy $\left(F_{v}\right)$ in unrecrystallized parts of $\gamma$. Since $F_{\mathrm{v}}$ decreases with the progress of recovery in $\gamma$ after deformation, the growth rate of recrystallizing $\gamma$ grain decreases rapidly immediately after deformation. Microalloying of $\mathrm{Nb}$ remarkably lowers the growth rate.

\section{Acknowledgement}

The authors are grateful to Dr. Hideo Yoshinaga, Professor Emeritus of Kyushu University for the helpful discussion held with him.

\section{REFERENCES}

1) H. Sekine, T. Maruyama and Y. Kawashima: Proc. Int. Conf. on Thermomechanical Processing of Microalloyed Austenite, AIME, Warrendale, (1982), 141.

2) M. Umemoto: Physical Metallurgy of Thermomechanical Processing of Steels and other Metals, ISIJ, Tokyo, (1988), 769.

3) C. M. Sellars: Proc. Int. Conf. on Working and Forming Process, Metal Society, London, (1980), 3.

4) Y. Saito: Simulation of Hot Working and Transformation of Austenite, ISIJ, Tokyo, (1985), 72.

5) W. Roberts, A. Sandberg, T. Siwecki and T. Werlefors: Proc. Int. Conf. on Technology and Applications of HSLA Steels, ASM, Materials Park, (1983), 67.

6) T. Senuma, H. Yada, Y. Matsumura and T. Futamura: Tetsu-toHagané, 70 (1984), 2212

7) P. Chouquet, A. Le Bon and Ch. Patrix: Proc. 7th Int. Conf. on Strength of Metals and Alloys, (1985), 1025.

8) A. Yoshie, T. Fujita, M. Fujioka, K. Okamoto and H. Morikawa: ISIJ Int., 36 (1996), 467.

9) A. Yoshie, T. Fujita, M. Fujioka, K. Okamoto and H. Morikawa: ISIJ Int., 36 (1996), 474.

10) H. Yada: Simulation of Hot Working and Transformation of Austenite, ISIJ, Tokyo, (1985), 40.

11) ASTM Designation: E112-88.

12) S. S. Hansen, J. B. Vander Sande and M. Cohen: Metall. Trans., 11A (1980), 387

13) W. A. Johnson and R. F. Mehl: Tians AIME., 135 (1939), 416.

14) M. Avrami: J. Chem. Phys., 7 (1939), 1103.

15) R. A. Vandermeer and P. Gordon: Recovery and Recrystallization of Metals, Interscience, (1963), 211.

16) K. Amano, T. Hatomura, M. Koda, C. Shiga and T. Tanaka: Proc. Int. Conf. on Accelerated Cooling of Steel, AIME, Warrendale, (1986), 349.

17) J. W. Cahn: Acta Metall., 4 (1956), 449

18) H. Abe: Recrystallization, Kyouritsu-Shuppan, Tokyo, (1969).

19) Japan Inst. Metals: Dislocation Theory (new edition), Maruzen, Tokyo, (1975).

20) M. Umemoto: Simulation of Hot Working and Transformation of Austenite, ISIJ, Tokyo, (1985), 24. 
21) S. Akamatsu, H. Yada, T. Senuma, Y. Matsumura and S. Ishikawa: Tetsu-to-Hagané, 75 (1989), 933.

22) Iron and Steel Handbook Vol. I (3rd edition), ed. by ISIJ, Maruzen, Tokyo, (1981), 492.

23) M. Umemoto and I. Tamura: Netsu Shori (J. Jpn. Soc. Heat Treat.), 24 (1984), 334.
24) A. Yoshie, M. Fujioka, H. Morikawa and Y. Onoe: Physical Metallurgy of Thermomechanical Processing of Steels and Other Metals, ISIJ, Tokyo, (1988), 799.

25) J. J. Jonas: Recrystallization '90, TMS, Wollongong, (1990), 27.

(Originally published in Tetsu-to-Hagané, 80 (1994), 920, in Japanese) 